REVISTA ANDALUZA DE ANTROPOLOGÍA

NÚMERO 21: PERSPECTIVAS ANTROPOLÓGICAS SOBRE EL ESTUDIO DE LA CAZA RECREATIVA ANTHROPOLOGICAL PERSPECTIVES ON RECREATIONAL HUNTING

DICIEMBRE DE 2021

ISSN 2174-6796

[pp. 103-122]

https://dx.doi.org/10.12795/RAA.2021.21.06

\title{
CAÇA E CONSERVAÇÃO NO PANTANAL BRASILEIRO: $O$ CASO DA ONÇA-PINTADA
}

\section{HUNTING AND CONSERVATION IN THE BRAZILIAN PANTANAL: THE CASE OF THE JAGUAR}

Felipe Süssekind

Pontifícia Universidade Católica do Rio de Janeiro

\section{RESUMO}

O ponto de partida para este artigo é um breve relato de viagem ao Pantanal do Mato Grosso do Sul, no Brasil, a uma fazenda que abrigava um canil especializado na captura de onças-pintadas para estudos científicos. Um lugar onde a pecuária coexiste com o ecoturismo e com projetos de conservação da biodiversidade. O diálogo entre o material etnográfico que apresento e alguns registros e documentos disponíveis sobre a história da fazenda revela diferentes camadas das relações regionais com as onças, contrastando o animal considerado nocivo no passado com a espécie ameaçada que atualmente é foco do interesse conservacionista. O objetivo é refletir sobre contrastes e composições possíveis entre atividades ligadas à biologia da conservação e costumes ligados ao modo de vida pantaneiro, tendo como ponto de partida uso de cães farejadores para captura de animais em estudos científicos

Palavras-chave: Caça; Conservação; Onça-pintada; Pantanal; Coexistência humanofauna; Cães de caça. 


\begin{abstract}
The starting point for this article is a brief report of a trip to the Pantanal of Mato Grosso do Sul, Brazil, to a farm that was home to a kennel specialized in capturing jaguars for scientific studies. It is a place where livestock farming coexists with ecotourism and biodiversity conservation projects. The dialogue between the ethnographic material I present and some available records and documents about the history of the farm reveals different layers of regional relations with jaguars, contrasting the animal considered harmful in the past with the endangered species that is currently the focus of conservation interest. The objective is to reflect on possible contrasts and compositions between activities related to conservation biology and activities related to the Pantanal traditional way of life, regarding the use of hunting techniques with hounds to capture animals in scientific studies
\end{abstract}

Keywords: Hunting; Conservation; Jaguar; Pantanal; Human-wildlife coexistence; Hounds.

\title{
INTRODUÇÃO
}

Em março de 2006, depois de alguns contatos via e-mail, fiz uma primeira viagem ao Pantanal para conhecer um projeto de conservação desenvolvido pelo Instituto OnçaPintada (IOP) no Município de Aquidauana, no Mato Grosso do Sul ${ }^{1}$. O projeto era sediado na Estância Caiman, fazenda de 57 mil hectares onde a criação de gado coexiste com o ecoturismo e com diferentes atividades voltadas para a conservação da vida selvagem. Pantanal é nome que se dá, no Brasil, ao bioma composto pelas planícies alagáveis da bacia do rio Paraguai, no extremo oeste do país. Reconhecido pela enorme biodiversidade, trata-se de uma região considerada pela Unesco como Patrimônio Natural Mundial e Reserva da Biosfera. Para a conservação da onça-pintada (Panthera onca), em particular, o Pantanal é uma área crítica na medida em que abriga um dos últimos grandes remanescentes populacionais de uma espécie altamente ameaçada pela pressão antrópica no território brasileiro².

1. O Instituto Onça-Pintada, com sede em Goiás, foi fundado por Leandro Silveira e Anah Tereza de Almeida Jácomo em 2002. http://jaguar.org.br/.

2. A espécie é qualificada como "quase ameaçada" pela União Internacional para a Conservação da Natureza, e "vulnerável” pela lista vermelha do Instituto Brasileiro do Meio Ambiente. Ver, a esse respeito: https://www.icmbio.gov.br/portal/images/stories/biodiversidade/fauna-brasileira/ avaliacao-do-risco/carnivoros/on\%C3\%A7a-pintada Panthera onca.pdf. 
O IOP investigava questões relacionadas à dieta, ao uso do território e outros aspectos do comportamento das onças ${ }^{3}$ nesta região, a partir principalmente de equipamentos de rádio-telemetria e armadilhas fotográficas. A captura de novos animais para colocação de colares de rádio mobilizava não só a equipe do projeto, mas também toda a comunidade da fazenda. Vivenciar de perto uma tentativa de captura significou, para mim, na ocasião, uma iniciação meio abrupta ao trabalho de campo para minha tese de doutorado, na qual procuraria abordar a conservação da onça-pintada de uma perspectiva antropológica.

Fazendas com milhares de cabeças de gado se estendem por quase todo o Pantanal, e a Estância Caiman abrigava um rebanho com cerca de 34 mil cabeças de gado em 2006, no momento em que visitei a fazenda. A produção de gado de corte é o motor de toda a economia pantaneira, ligada a uma das indústria mais fortes do agronegócio no Brasil, a indústria da carne bovina. A escala industrial da produção da pecuária contrastava, entretanto, com a simplicidade da pequena comunidade rural. Um sistema conectado ao capitalismo industrial de grande escala em fricção com os costumes e práticas locais ${ }^{4}$. Os moradores da Estância Caiman -incluindo vaqueiros e suas famílias, administradores, técnicos, motoristas e todo o pessoal ligado ao ecoturismo- viviam em pequenas comunidades conectadas por estradas e via rádio. Além da sede, onde ficava a vila principal, havia na fazenda outro quatro pequenos núcleos familiares, ou "retiros", cada um deles responsável por uma parte do gado da fazenda ${ }^{5}$.

Fui apresentado ao Instituto Onça Pintada por duas pesquisadoras ligadas à medicina veterinária, Mariana Furtado e Cyntia Kashivakura. Um dos aspectos do projeto de pesquisa na fazenda envolvia o estudo da interação entre animais domésticos e silvestres a partir da transmissão do rastreamento de doenças infecciosas, o que dependia da coleta de amostras biológicas das onças. Uma captura estava sendo preparada por elas, e no dia seguinte à minha chegada acompanhei a equipe do projeto ao Canil Jaguaretê, no qual eram criados cães especializados em seguir o rastro das onças-pintadas. A caçada praticada no Pantanal é baseada no uso de cães farejadores, "onceiros", e pude perceber

3. O termo não marcado "onça" se refere, em geral, no Brasil, à onça-pintada (Panthera onca). A palavra "jaguar", usada mais raramente no português, tem origem em idiomas indígenas tupi-guarani, falados no Brasil em outros países sul-americanos. É utilizada na maior parte das Américas, inclusive nos países falantes do inglês, mas curiosamente não no Brasil, onde prevalece o termo "onça", de origem europeia. Sobre os muitos nomes populares para designar a espécie, ver o trabalho de Papavero (2017).

4. Fricção' foi o termo usado por Anna Tsing (2005) para descrever a passagem do local ao global, ou a interconexão entre os fluxos do capital e as ecologias regionais.

5. Um retiro é um local afastado da sede da fazenda composto por casas de moradores e, em geral, um cercado, ou "mangueiro", onde se trabalha com o gado, além de galpões, estábulo e outras instalações usadas para o trabalho rural. 
logo de saída que a conversão destes -assim como de vaqueiros e antigos caçadoresem agentes conservacionistas era um assunto que envolvia a ressignificação de alguns costumes tradicionais.

\section{CAPTURA}

O caminho até o Retiro Novo, a $15 \mathrm{~km}$ da sede, foi percorrido na caminhonete do administrador da fazenda, que a princípio não fez muita questão de ser simpático. "Antropólogo? Têm muito antropólogo aí para defender os índios, mas nenhum para defender o fazendeiro", me disse. Depois disso, entretanto, concordou em dar um depoimento para a minha pesquisa. Falando sobre o canil, comentou que "antigamente um bom cachorro onceiro valia vinte cabeças de gado, quando era cachorro bom mesmo, mestre". Contou em seguida que o avô dele tinha vindo do Rio Grande do Sul para o Pantanal. "Naquele tempo tinha muita onça. E o gado era criado sem cerca, tudo no laço e no berrante". Por fim fez uma referência ao "bagual", o gado em estado feral, "brabo", que existia na fazenda no passado. O estatuto do gado bagual, como eu iria constatar mais tarde, era ambíguo. Se por um lado ele podia ser referido como um índice de abandono, ou "atraso", por outro podia ser uma fonte de afirmação da identidade pantaneira, uma prova de coragem lembrada com nostalgia.

A pequena vila do Retiro Novo era formada por um conjunto de casas em torno de um grande curral, ou "mangueiro", onde se trabalha com o gado. Tinha dezoito moradores quando estive lá, incluindo adultos e crianças. Um rebanho de mais de dez mil cabeças estava sob os cuidados dessa pequena comunidade familiar. O mangueiro é onde os animais do rebanho são contados, vacinados, marcados e pesados, sendo a produção da fazenda comercializada para açougues e frigoríficos nas cidades próximas de Miranda e Aquidauana.

O trabalho com o gado, conforme me explicaram, é dividido em funções. O praieiro é quem cuida das casas e do material de montaria; o tropeiro, em geral o mais novo do grupo, é quem sai cedo para reunir os animais de montaria (a "tropa"), "o primeiro a acordar e o último a dormir". O salgador de coxo percorre a fazenda colocando sal e nutrientes para o gado. O campeiro, por sua vez, é aquele que trabalha à cavalo, na lida diária com o rebanho. O capataz é o responsável pelo retiro e um dos campeiros mais velhos é o encarregado, o segundo no comando. A esposa do capataz é a responsável pela "cantina", localizada em um salão anexo à cozinha da casa do casal, onde vaqueiros e outros funcionários da fazenda, assim como pesquisadores e guias de turismo, fazem suas refeições.

Assim como diferentes tipos de vaqueiros, há tambén diferentes tipos de gado. Uma pe alguns bois "sinuelos", usados para conduzir a boiada, vivem nas pequena quantidade de vacas leiteiras, que produzem para o consumo interno, 
proximidades das casas dos moradores. Este gado manso é reconhecido individualmente, "tem até nome". O gado de corte, por outro lado, criado em uma escala centenas de vezes maior, é numerado e fica distribuído em lotes pelas invernadas da fazenda, dividido em classes de idade. A fazenda comercializa em geral os novilhos, enquanto mantém as novilhas. $\mathrm{O}$ abate semanal e a carneação, feitos pelos próprios vaqueiros, são parte da rotina em lugares como o Retiro Novo. Para o consumo interno, são abatidas as "matulas", escolhidas entre as vacas que não produzem mais.

O gado é alimento, mas também fornece matéria-prima para utensílios como a tralha de montaria, ou a "guampa" feita de chifre, usada para se tomar o mate gelado, o "tereré". Um dos atributos mais importantes de um vaqueiro, porém, é a habilidade com o laço, o que vale tanto para os laçadores quanto para os artesãos. A fabricação do laço é um processo que começa com preparação do couro, passando pelo corte em formato espiral, até chegar no trançado, que é a parte mais difícil. Um bom laço é muito valorizado. Dizem que "o laço é a arma do campeiro". Há pequenas competições internas com frequência, e campeiros de toda a região representam as fazendas onde trabalham em vaquejadas como as organizadas pelo Clube do Laço, na cidade de Miranda, envolvendo prêmios em dinheiro e prestígio esportivo.

No Retiro Novo, os moradores casados viviam com suas famílias em casas cedidas pela fazenda, enquanto os solteiros moravam em uma construção maior, o "galpão", onde ficava também a base de campo do Instituto Onça-Pintada. Esta última, onde fiquei hospedado, incluía acomodações para pesquisadores e um pequeno laboratório com o equipamento e a estrutura básica para o trabalho de campo.

Os animais de estimação dos moradores foram banidos da Estância Caiman a partir do momento em que a área se tornou Refúgio Ecológico, em 1985. Duas décadas depois, o resultado era que animais selvagens como lobinhos, tamanduás, emas e queixadas eram vistos com frequência, além de numerosos bandos de capivaras e jacarés. A exceção em relação à presença dos cães na fazenda era o Canil Jaguaretê. Composto de uma estrutura coberta, dividida em baias e conectada a uma área externa cercada, o canil abrigava exemplares de foxhounds, bloodhounds e coonhounds, alguns importados dos EUA. Os nomes dos cachorros -Zagaia, Berrante, Bugio, entre outros- faziam referência às tradições locais, sendo os dois últimos ligados ao latido, ou "barruar", característico das raças de caça. O único "mestre", no entanto, era um pequeno vira-lata, "importado de uma fazenda vizinha", chamado de Mestrinho. O que fazia dele um mestre, disseram-me, era o fato de que seguiria apenas o rastro da onça, e de nenhum outro animal.

A primeira tentativa de captura que presenciei aconteceu dois dias depois dessa visita ao canil. A caminhonete do projeto partiu de manhã bem cedo, com a cachorrada na 
caçamba, depois do aviso de que um vaqueiro havia localizado um bezerro predado pela onça. Uma parte da equipe seguiu à cavalo. Eles contavam com a ajuda de um fazendeiro vizinho com experiência em caçadas, que ia numa segunda caminhonete. Eu e um estagiário do projeto, também recém chegado, fomos avisados de que não poderíamos acompanha-los, então passamos a manhã na base de campo ouvindo as notícias pelo rádio. Assim ficamos sabendo que chegaram a "acuar" a onça em determinado momento, mas no final ela acabou escapando.

O felino costuma subir em uma árvore quando cercado pelos cachorros, onde se torna um alvo fácil para o caçador humano armado. Mas ao invés disso, este tinha se embrenhado no "carandazal", um mato fechado e cheio de espinhos, de onde enfrentou seus perseguidores. Uma onça acuada no chão - no "sujo", como dizem-é uma situação extremamente perigosa. O resultado foi que o cão líder, Mestrinho, ficou ferido, com cortes na altura das costelas. "Foi unhada. Se a onça morder, ela mata", comentou Cyntia, a veterinária, enquanto limpava e suturava os fermentos.

No final da tarde, acompanhei os integrantes do projeto - além das duas pesquisadoras, um técnico em zoologia e um estagiário- até o galpão onde os vaqueiros guardavam os apetrechos de montaria. Eles estavam reunidos em roda para tomar o tereré, e a conversa era animada pelos acontecimentos do dia. "Não subiu", comentou um dos vaqueiros. "Essas onça daqui são braba, fica no caraguatazeiro", observou o técnico do projeto. Um dos moradores mais antigos do retiro, seu Vicente, o encarregado, contava alguns "causos" que foram recebidos com muitas risadas.

Reproduzo um deles a partir das minhas notas. A história começa com um homem (um fazendeiro?) que chama um caçador para ir atrás de uma onça. Os cachorros encontram uma "batida" e seguem no rastro da onça. O caçador segue atrás deles. Mas o homem fica para trás, esperando sozinho. Só que a onça, esperta, tinha rodeado e voltado para perto de onde ele tinha ficado esperando. Distraído pelo barulho dos cachorros, o sujeito não tinha visto a onça subindo numa árvore alta logo atrás dele. Logo depois, ouve o barulho do caçador vindo na sua direção com os cachorros, mas acha que ela vem na frente e, na fuga, escala a mesma árvore alta. Quando o caçador chega e olha pra cima, vê o homem e a onça na mesma árvore. E fala: "não precisa pegar ela sozinho aí em cima não, deixa que eu atiro aqui de baixo". Nisso, o cabra vê a onça em cima dele e, com o susto, despenca lá de cima, rolando "feito um quati" pelo chão. A cachorrada, achando que é um bicho, parte pra cima e acaba com ele antes que o caçador possa fazer nada.

Todos riram bastante da história. Era uma provocação bem humorada aos integrantes do projeto, endereçada principalmente ao técnico de campo, Eduardo Freitas, apelidado de Negão. Os campeiros se divertiam e implicavam com ele, que por sua vez exagerava 
na valentia com que tinha enfrentado a onça mais cedo. Meu comentário, anotado na época, foi que as relações que os vaqueiros tinham com os integrantes do projeto eram uma transformação daquelas que tinham, no passado, com os caçadores. Entravam em contato quando achavam rastros ou animais abatidos, acompanhavam e participavam das caçadas (ou capturas), e por aí vai. Referiam-se aos pesquisadores como quem "mexe com onça", assim como eles mesmos "mexem com o gado".

Desde as primeiras capturas de onças no âmbito de projetos científicos no Pantanal, o método tradicional da caçada com cães mostrou-se o mais eficaz ${ }^{6}$. O tema, porém, é controverso. Em artigo sobre os métodos de campo para o estudo das onças, Furtado e outros observam que "é importante se considerar que a caçada de onças-pintadas é proibida na maior parte dos países onde a espécie ocorre e a contratação de caçadores e cães de caça viola princípios legais e éticos" (Furtado et al., 2008: 41-42).

A controvérsia diz respeito, portanto, ao fato de que as onças foram historicamente perseguidas e eliminadas por fazendeiros através de caçadores e do uso de cães, e em muitos lugares continuam sendo, apesar da proibição. Mas ao mesmo tempo, como vimos, esses mesmos cães podem ser decisivos para o estudo das onças. Um cachorro mestre é conhecido por rastrear apenas onças e nenhum outro animal. Mas se ainda hoje um cachorro desse pode ser valorizado como uma forma de eliminar as oncas, no contexto de um projeto conservacionista ele podia ser entendido como um aliado, um mediador que cria as condições para o uso das ferramentas de telemetria e GPS, fundamentais para a pesquisa de campo. O Canil Jaguaretê era uma experiência singular nesse sentido.

\section{A MIRANDA ESTÂNCIA E SEUS CAÇADORES}

"Nessa região, a turma já está mais pra proteger mesmo", afirma o Sr. Zé Carlos, capataz do Retiro Novo, em um registro em vídeo de março de 2006. "Eles trabalham com esse projeto, tem a proteção dela. E nós ajudamos essa turma aí. Todo mundo se empenha, ajuda". Ele é um senhor com cabelo grisalho e um bigode preto fino que acentua os traços indígenas. Pergunto se o pessoal da fazenda não fica chateado quando a onça pega um bezerro. "O patrão não liga não, diz pra deixar ela aî". Depois de passar adiante a guampa do tereré, conclui: "Um dia ela enjoa de comer"7.

6. Na última década, o método com armadilhas de laço tornou-se mais comum e substituiu, em muitos casos, o uso de cães nas pesquisas com onças-pintadas.

7. O patrão, no caso, é o empresário paulista Roberto Klabin. A fazenda foi pioneira no Ecoturismo e, desde 1985, é um refúgio ecológico onde são desenvolvidos uma série de projetos conservacionistas. 
Seu Zé Carlos conta ainda que chegou com dezessete anos na "Companhia", a fazenda que deu origem à Estância Caiman, "bem antes dela ser dividida". "E naquela época o pessoal matava muita onça?", pergunto. "Matava. Tinha caçador da fazenda mesmo pra matar. O serviço dele era só esse. Era chamado Celestino. Faleceu já. Quando ficou proibido, aí ele foi saindo, trabalhou de contador de gado depois também. Era homem de confiança do Major".

A história da Miranda Estância é um rico testemunho do processo de colonização da região sul do Pantanal, como mostra o trabalho dos historiadores Cezar Benevides e Nanci Leonzo (1999). Criada por investidores ingleses em 1912 para a produção de carne em sistema de charque, carne seca para ser enlatada, The Miranda Estância Company Limited, a "Companhia", chegou a ocupar uma área de inacreditáveis 219.506 hectares (Benevides e Leonzo, 1999: 25), praticamente o dobro do tamanho do município do Rio de Janeiro. Em 1952, a fazenda foi comprada por empresários brasileiros a partir do movimento conhecido como "Marcha para o Oeste", o processo de nacionalização empreendido pelo presidente Getúlio Vargas (ibidem: 148-149). O caçador ao qual seu Zé Carlos se refere é Celestino Prudêncio da Silva, conhecido como "bugre Celestino" (ibidem: 131), um personagem marcante na história da fazenda. O major é o major Alfredo Ellis Netto, descrito pelos historiadores como "um bandeirante moderno" (ibidem: 18), que foi o administrador da propriedade até os anos 1970.

Outros personagens que fazem parte da história da Miranda Estância são dois biólogos: Peter Crawshaw e Howard Quigley. Entre 1980 e 1984, eles desenvolveram na fazenda um projeto pioneiro na área da Biologia da Conservação, envolvendo monitoramento de onças-pintadas em vida livre. Coordenado inicialmente por George Schaller, o célebre naturalista norte americano, o projeto era fruto de uma parceria entre a New York Zoological Society, atual Wildlife Conservation Society (WCS), o Instituto Brasileiro de Desenvolvimento Florestal (IBDF), órgão ambiental brasileiro na época, e a Fundação Brasileira para a Conservação da Natureza (FBCN) (Crawshaw, 2006).

A primeira base de campo de George Schaller no Pantanal, implantada numa área vizinha ao que é hoje o Parque Nacional do Pantanal Mato-Grossense ${ }^{8}$, havia sido inviabilizada pelo conflito entre criadores de gado e os felinos, e a pesquisa chegou à Miranda Estância em 1980. Schaller teve que deixar o Pantanal nessa época e trouxe Howard Quigley para substitui-lo (Schaller, 2007). Já sob responsabilidade de Crawshaw e Quigley, o projeto encontrou na fazenda as condições necessárias para sua implementação: uma postura

8. Criado em 1981 eadministrado pelo Instituto Chico Mendes de Conservação da Biodiversidade (ICMBio) 
conservacionista consolidada, apoio da comunidade local e uma boa infraestrutura para as atividades de campo, incluindo acomodações, estradas, animais de montaria e pista de pouso (Crawshaw, 2006).

Um dos grandes desafios para a conservação do jaguar no Pantanal, entretanto, era o tratamento historicamente dispensado à espécie no contexto da pecuária tradicional. No relatório final do projeto, escrito para o então IBDF, Crawshaw e Quigley afirmam:

"Até 1966, a fazenda Miranda Estância contratava caçadores profissionais para diminuir o número de felinos e a sua predação no gado. Um desses caçadores matou, em um período de 8 anos (1959-1966), 68 pintadas e 275 pardas, apenas na área da fazenda” (Crawshaw e Quigley, 1984).

Os biólogos se referem aqui ao mesmo caçador mencionado pelo capataz, Celestino, com quem conviveram na Miranda Estância. Ele era reconhecido como um "zagaieiro", termo reservado aos antigos caçadores nativos do Pantanal. Filho de uma índia bororo e de um homem branco de Cuiabá, o Bugre Celestino é um personagem que remete a um tempo no qual a caçada de onças na fazenda era uma atividade regular. "Zagaia" é o nome que se dá a um tipo de lança usada no passado para caçadas de onças, e os zagaieiros são lembrados com frequência quando os moradores do Pantanal se referem aos tempos antigos?.

Não cheguei a conhecer pessoalmente seu Celestino, que faleceu em 2005, um ano antes da minha visita à fazenda. Mas tive a oportunidade, em 2008, de registrar um depoimento do sr. Getúlio dos Santos, genro dele, que também tinha sido funcionário da Miranda Estância, afirmando o seguinte:

"Ele [Celestino] aprendeu com o sogro dele, muito tempo atrás, quando era solteiro ainda. Diz que tinha um ditado assim, que para casar com a filha dele tinha que pegar uma onça na zagaia. Ele gostava dela, aí teve que encarar o velho e pegar a onça”.

A partir de um trabalho baseado em levantamento bibliográfico sobre o grupo indígena Guató, que habitava no passado o alto rio Paraguai e o São Lourenço, Oliveira (1996) refere-se a uma relação semelhante envolvendo sogro-genro. A caçada de onça, diz o

9. Inspirado em parte pelas viagens de Guimarães Rosa ao Pantanal, o conto "Meu tio o Iauaretê", de 1961, traz como personagem um zagaieiro de origem indígena que vai "desonçar" uma região destinada à criação de gado. Uma história de transformação na qual a marginalidade da herança indígena se articula com um movimento de devir animal. 
autor, “[f]az parte também de uma espécie de rito de passagem dos jovens (...), pois cada onça caçada poderia dar direito a uma esposa” (1996: 109).

Outro exemplo significativo da tradição regional de caçadas é Sasha Siemel, um caçador e escritor nascido na Letônia que viveu na Miranda Estância na primeira metade do século $\mathrm{XX}$, onde trabalhou como guia de safáris. Siemel publicou alguns livros de aventura de teor autobiográfico, nos quais relata suas caçadas. O primeiro deles, Tigrero!, de 1953, narra o encontro do autor com um zagaieiro chamado Joaquim Guató. Há, no livro, um contraste forte entre as imagens do indígena corrompido pela bebida, de um lado e, de outro, o perfeito caçador, dotado de "qualidades e instintos quase sobre humanos" (Siemel, 1953: 27) ${ }^{10}$. Um retrato eloquente do colonialismo: o protagonista branco que absorve os conhecimentos indígenas e os incorpora ao seu ideal civilizatório. Tigrero! é um exemplo interessante das fronteiras entre a narrativa de aventura e a descrição naturalista, onde o ideal de dominação da natureza, na figura da onça-pintada, se confunde com uma naturalização do encontro colonial.

Siemel retrata o "tigre"11 como um inimigo honrado e descreve a experiência do enfrentamento da fera como algo que extrapola o código da nobreza esportiva, colocando em risco a própria vida do caçador. Ao mesmo tempo, apresenta em segundo plano o sacrifício do animal como algo necessário, um serviço para a comunidade. A descrição do animal nocivo aparece no livro, por exemplo, quando o autor se refere a uma palestra que deu em um clube de caça, em Nova York, na qual é questionado sobre a importância de se preservar os animais selvagens: "Eu expliquei", diz ele, "que também não gostava de matar animais, e que minha caçada era para abater um animal assassino, do mesmo modo que um policial seria capaz de matar um assassino humano" (ibidem: 274). Neste outro trecho se refere não ao jaguar mais ao puma: "O puma era um destruidor de gado, e um dos raros animais da selva que matam unicamente por matar [...] Eles [pumas] são covardes" (ibidem: 276, grifos meus).

Os termos usados para descrever os animais no livro - "assassino", "covarde", "demônio"contrastam, com as características de nobreza, bravura e honra da fera enfrentada pelo zagaieiro: "Você vai ver que o tigre não responde à lógica humana, e não entende o significado de piedade. E o tigre é um dos inimigos mais honrados que você irá encontrar" (ibidem: 16). A ambiguidade entre o animal nocivo e o adversário de valor atravessa

10. Tradução minha.

11. Escrevendo em inglês, Siemel usa estranhamente o termo "tigre", ao invés de "jaguar" usado em diversas línguas inclusive o inglês, ou "onça", mais comum no português e usado no Pantanal 
toda a narrativa, e é esta ambiguidade que define a identidade heroica do caçador como alguém capaz de eliminar uma ameaça e ao mesmo tempo sobrepujar a natureza na figura deste "inimigo honrado".

A onça é o adversário contra o qual o autor prova suas qualidades e preenche seu espírito. Siemel descreve a partir daí sua transformação em um tipo especial de caçador, o zagaieiro que enfrenta sozinho o "tigre" (onça-pintada) armado apenas com uma lança, representando "o homem contra a natureza nos mais primitivos termos" (Siemel, 1953: 27). Um retrato idealizado da essência da caçada, que o autor teria sido o "primeiro homem branco" a experimentar.

No decorrer da minha pesquisa de campo no Pantanal tive contato com uma coleção de fotografias proveniente do acervo de Siemel, exposta em um salão de visitas da Pousada Fazenda San Francisco, em Miranda (MS) ${ }^{12}$. A situação mais repetida nas imagens era de caçadores em torno da onça abatida. Siemel, a mulher e o filho pequeno sorridentes, aparecem portando zagaia, espingarda ou arco e flecha, quase sempre agachados atrás do corpo de um animal morto em primeiro plano. Uma foto em que o caçador abre a boca do felino para mostrar as presas para a câmera. Um retrato de Joaquim Guató. Pendurada no alto da parede, a zagaia -uma lança com dois metros de comprimento e uma ponta de ferro tripartida na base.

A coleção incluía também instantâneos das imagens em vídeo que tornaram Siemel famoso, nas quais ele enfrenta onças em um cercado construído na área da sede da fazenda. Analisando os livros contábeis e outros documentos da Miranda Estância, Benevides e Leonzo chamam atenção para o caráter artificial do personagem autobiográfico que Siemel construiu, mostrando que usava armas e munições com regularidade em suas expedições de caça:

"[E]stamos diante de um homem inteligente que utilizou o Pantanal mato-grossense para sobreviver, mas, com certeza, não apenas com a zagaia. Os livros e documentos contábeis da The Miranda Estância Company Limited comprovam sua ligação com os caçadores da fazenda (...) e o denunciam como habitual comprador de munições" (1999: 89).

Os autores chamam atenção ainda para o fato de que os caçadores que trabalhavam na fazenda, e acompanharam Siemel durante muitos anos, não são citados em nenhum momento nos livros dele. Isso os leva a concluir que "a questão do uso exclusivo da zagaia é uma farsa, que funcionava apenas com animais domados" (ibidem). Eles nos

12. Algumas imagens significativas do acervo de Siemel podem ser observadas em https:// tokdehistoria.com.br/2013/04/27/conheca-sasha-siemel/. 
lembram também, nesse sentido, que a caça, além de uma prova de coragem, tinha uma função econômica, sendo que as peles dos jaguares mortos pelos caçadores faziam parte dos balanços da Miranda Estância.

A capa do livro de Benevides e Leonzo traz uma fotografia de dois homens agachados junto a uma onça-parda. Um deles traz, apoiada no joelho esquerdo, uma zagaia, e segura com as duas mãos a cabeça inerte do felino. A legenda da imagem nos informa um deles é Lauro Alves, um dos caçadores pantaneiros trabalhou na com Sasha Siemel. Uma referência a ele pode ser encontrada também no livro Jaguar Hunting in Mato-Grosso, publicado em 1976 por Tony Almeida, um guia de caça e escritor ligado à tradição naturalista:

"A técnica de atacar o jaguar com a lança, que o velho tinha aprendido com Siemel, exigia exatamente aquele temperamento frio e determinado. Lauro tinha sido o braço direito de Siemel por muitos anos e matado meia dúzia de jaguares sozinho, armado apenas com uma lança”.

Agora uma etiqueta presa no crânio branqueado sobre a lareira do Major, com o CPN Fس山س山 EFhome de Lauro, a data e a medida escritas nela, eram o único testemunho daquela batalha solitária e da proeza do homem que combateu o gato monstruoso com[VNB arma tão primitiva quanto as usadas por seusantepassados pré-históricos $\mathbb{W}^{\prime}$ W $\mathrm{FEB}$, 1976: 10)Ш.

A descrição corrobora mais uma vez a construção dessa imagem em que a luta do zagaieiro com a onça representa ao mesmo tempo um retrato essencial da caçada, nos "mais primitivos termos", e a domesticação da natureza vinculada a um ideal de cientificidade e correção civilizatória.

\section{CAÇA E CONSERVAÇÃO}

Nos trechos de Siemel que citei acima, como nesse último de Almeida, podemos ver como a dimensão do enfrentamento se insere em uma certa antropologia espontânea, na qual uma certa imagem do Animal -a "fera"- produz por contraste uma certa imagem do Humano -aquele que a vence. A caça é submetida então a uma moralização, ou domesticação, no sentido de que é apresentada como algo que enobrece um tipo específico de caçador - um caçador branco, ilustrado, que de preferência envia exemplares dos animais caçados para museus de história natural, ao mesmo tempo que protege o patrimônio dos fazendeiros. Vale lembrar também que ambos os autores eram guias de caça procurados por turistas de diversas partes do mundo, que viviam dessa atividade.

13. Tradução minha. 
Podemos imaginar a figura de Theodore Roosevelt como uma espécie de "pai fundador" para essa série de fontes literárias sobre caçadas de onça. No ano de 1913, em companhia do Marechal Rondon, Roosevelt fez sua conhecida expedição pelo Brasil. O livro que publicou a partir dela no ano seguinte, Nas selvas do Brasil, descreve as caçadas de onça que o autor fez no Pantanal, antes de partir em sua missão civilizatório-cartográfica de desbravar o Rio da Dúvida (Roosevelt, 1976).

Em seu fascinante trabalho de sobre o American Museum of Natural History, em NY, Donna Haraway descreve com precisão, a partir da figura de Roosevelt como patrono, a conexão entre a história natural e a versão norte-americana do colonialismo. $\mathrm{O}$ título usado por ela é uma expressão, impossível de traduzir, que captura com precisão o espírito da coisa: "Teddy-Bear Patriarchy" (Haraway, 1989). O museu evoca um modelo literário e imagético que constrói artificialmente a ilusão de um olhar direto, sem mediação, no qual a natureza selvagem é dominada pelo protagonista masculino da história natural, "men, the hunter". O herói que enfrenta a fera. A conquista civilizatória do território selvagem.

$\mathrm{Na}$ literatura sobre caçadas de onça, os caçadores nativos, "zagaieiros", são referidos ora como heróis capazes de enfrentar sozinhos a onça (Siemel, 1953), ora como ajudantes subalternos do caçador armado (Pereira da Cunha, 1949). Mas quais seriam as continuidades e rupturas entre as descrições desses caçadores-naturalistas e o modo de vida pantaneiro? A não ser pelas pistas reunidas por Benevides e Leonzo (1999), sabemos pouco sobre as relações de alguém como Sasha Siemel, por exemplo, quando viveu na Miranda Estância, com os fazendeiros, os patrões; e menos ainda sobre como ele era visto pelos vaqueiros e trabalhadores da fazenda.

O enfrentamento, por outro lado, é certamente um tema importante dentro das tradições orais e dos costumes pantaneiros. Álvaro Banducci, antropólogo que fez trabalho de campo na região do Pantanal da Nhecolândia, afirma:

"Na fazenda onde existe o gado bagual o peão se vê como 'autêntico', pois deve acordar cedo, ficar muitas horas sem comer e correr maiores riscos no campo, ao passo que enxerga no outro um vaqueiro indolente, fraquejado pela 'facilidade' do trabalho" (Banducci, 1995: 134).

Há, aqui, um tipo de transferência entre o vaqueiro e o animal que ele é capaz de dominar, ou amansar, e que lhe confere prestígio e valor. Banducci mostra que a identidade pantaneira se constrói no embate com uma dimensão indômita, com uma alteridade que precisa ser continuamente controlada, ou domada (1995: 110-113). Trata-se de um conjunto de relações nas quais o que está em jogo é menos domesticar do que domar, 
ou seja, nas quais opera muito mais um gradiente entre "brabo" e "manso" do que uma fronteira definitiva entre o animal doméstico e o selvagem. A "doma bruta" praticada com os cavalos, a cultura da vaquejada, ou as caçadas do porco-monteiro, são exemplos disso; assim como as antigas "bagualhações", onde o gado salvagem era pego à laço. Atividades que borram a fronteira entre a caça e a lida.

Ao longo de sua história, a fazenda Miranda Estância testemunhou, como se pode ver, muitas caçadas. E para os caçadores, de forma geral, sejam eles nativos ou visitantes vindos de fora do Pantanal, a onça-pintada sempre foi o grande "troféu", o adversário que confere prestígio. Há, entretanto, uma mudança significativa nas relações regionais com as onças, a partir principalmente da década de 1980, ligada à entrada em cena do turismo ecológico e ao crescente interesse conservacionistas na região do Pantanal. Nessa nova economia, as expedições de caça são substituídas pelos passeios turísticos, e o troféu passa a ser traduzido em registros fotográficos.

A implantação de um projeto de conservação das onças-pintadas na Miranda Estância, com chegada dos biólogos Peter Crawshaw e Howard Quigley, é um marco, nesse sentido, para o surgimento do novo paradigma ecológico. Seria, porém, um erro considerarmos que os novos papéis substituíram definitivamente os antigos. Referindo-se à experiência que tiveram em campo, os biólogos fazem o seguinte comentário:

"Embora essa atividade [a caça] tenha sido proibida a partir de 1966, o controle é difícil e, ocasionalmente, alguns animais são mortos para "diversão" dos peões e para treinar cachorros, uma vez que um bom cachorro onceiro e um revolver 38 são os maiores símbolos de status entre pantaneiros" (Crawshaw e Quigley, 1984).

É significativa aqui a menção à interrupção da caça no ano de 1966. A atividade da caça foi regulamentada por lei no Brasil no ano seguinte, 1967, quando foi declarada proibida para qualquer espécie da fauna silvestre nativa ${ }^{14}$. A legislação sobre o tema foi modificada em 1998, incluída na Lei de crimes ambientais ${ }^{15}$, estabelecendo punições mais severas para os infratores, mas o fato é que, na prática, muitos proprietários rurais pantaneiros

14. Está em pauta atualmente no Brasil um projeto de lei que propõe a revogação da lei de proteção à fauna, de 1967, e pretende regulamentar a caça no país. Muito criticado por organizações ambientalistas e de proteção a fauna, o Projeto de Lei 6268/16, é de autoria o deputado Valdir Colatto (PMDB-SC), membro da bancada ruralista. Ver: http://www1.folha.uol.com.br/ ambiente/2017/03/1865615-projeto-de-lei-quer-liberar-caca-de-animais-selvagens-no-pais. $\underline{\text { shtml }}$

15. Lei $\mathrm{n}^{\circ}$ 9.605, de 12 de fevereiro de 1998. http://www.planalto.gov.br/ccivil 03/leis/19605. htm. 
continuam até hoje a reivindicar o direito de abater animais que atacam o gado.

A pena, na legislação brasileira, é direcionada a quem "[m]atar, perseguir, caçar, apanhar, utilizar espécimes da fauna silvestre, nativos ou em rota migratória, sem a devida permissão, licença ou autorização da autoridade competente" ${ }^{16}$. Mas a legislação é ambígua para casos como o da onça-pintada. O artigo 37 da Lei 9.605, de 1998, afirma que "[n] ão é crime o abate de animal, quando realizado (...) para proteger lavouras, pomares e rebanhos da ação predatória ou destruidora de animais, desde que legal e expressamente autorizado pela autoridade competente"; ou "por ser nocivo o animal, desde que assim caracterizado pelo órgão competente". Silveira et al. (2008) apontam, nesse sentido, para a disparidade entre o rigor da legislação e a ausência de meios efetivos de aplicá-la.

Reinaldo Lourival, em um estudo sobre a sustentabilidade do modelo de caça tradicional realizado na sub-região da do Pantanal da Nhecolândia, aponta o porco-monteiro, uma espécie exótica, como o animal de preferência na caça de subsistência local (1997: 123124). O autor estuda comparativamente as quantidades de animais domésticos e de animais silvestres consumidos em fazendas da região, assim como o cálculo de densidade das espécies desses últimos, e, a partir daí considera que o modelo de caça na região é tende a ser sustentável:

"A popularidade do porco-monteiro como espécie prioritária na caça tradicional tem um componente extremamente positivo no que tange à conservação do restante da fauna cinegética da Nhecolândia. É seguro afirmar que se esta espécie não tivesse se estabelecido na região, certamente ocorreria uma pressão de caça adicional sobre todas as outras espécies com potencial cinegético" (1997: 157).

Considerado uma raça de suíno pantaneira, o porco-monteiro é uma transformação feral do porco doméstico (Sus scrofa domesticus) ${ }^{17}$. Adaptado ao ambiente local, o bicho passa por uma mudança morfológica significativa, e sua carne e a gordura são bastante apreciadas pelos moradores das fazendas onde ele ocorre. Quando os vaqueiros encontram um porco ainda jovem, eles vão atrás dele e o laçam, como fazem com os garrotes, depois amarram e castram, ali mesmo no campo. Neste caso, um corte na orelha ou no rabo é usado para marcar o animal. A lógica é a mesma que se usa para o gado. O animal inteiro é o "guaiaco". O "capado" é aquele que vai ser caçado, depois que for considerado suficientemente gordo.

16. Lei No 9605-12/03/1998. Art. 29.

17. Ver a esse respeito: https://www.embrapa.br/busca-de-publicacoes/-/publicacao/853316/ ecologia-de-populacoes-de-porco-monteiro-no-pantanal-do-brasil. 
Aprendi isso no período em que estive na Estância Caiman, quando um desses porcos foi avistado durante a tentativa de captura da onça e abatido por um funcionário da fazenda. Depois disso foi levado para a cantina para ser servido na refeição oferecida aos moradores e visitantes no dia seguinte. Vale lembrar que a fazenda era um refúgio ecológico, sendo que os animais nativos eram o grande atrativo para o turismo. Com exceção da caçada com cães para captura das onças, a caça eventual ao porco-monteiro era a única permitida na propriedade.

Quando se refere ao caso do porco e à sustentabilidade do modelo de caça tradicional, Reinaldo Lourival faz a seguinte ressalva:

“Com relação às espécies daninhas, as análises devem ser interpretadas com cuidado. As onças-pintadas já foram praticamente eliminadas da região [a Nhecolândia]. As pardas, por sua vez, sofrem perseguição (...) frequente no Pantanal” (1997: 162).

De fato, a caça por retaliação à predação do gado é, até hoje, apontada como uma das maiores ameaças para as onças no Pantanal, onde existe há muitos anos uma prática regular de caça envolvendo a eliminação sistemática dos predadores. Desde os antigos safaris até os dias atuais, se constituiu uma técnica específica envolvendo as habilidades combinadas dos cães farejadores e dos caçadores humanos. Nesse sentido, quando pensamos nas possibilidades de coexistência humano-fauna, é significativa, e bastante singular, a experiência envolvendo a colaboração dos de caçadores nativos e de cães de caça em projetos conservacionistas.

\section{CONCLUSÕES}

A partir do trabalho feito na Miranda Estância, Crawshaw e Quigley confirmaram que o gado era uma fonte de alimento regular, e não esporádica, para as onças-pintadas nesta região do Pantanal (Crawshaw e Quigley, 1984). A disponibilidade de bovinos era muitas vezes maior, em termos de biomassa, do que da soma de todas as outras espécies que faziam parte da dieta das onças, o que fazia do gado o alimento mais abundante localmente para a espécie. Não por acaso, desde essa época, a necessidade de lidar com aqueles que veem a onça como uma ameaça e a busca de um modelo participativo têm sido aspectos fundamentais nas discussões sobre a conservação da espécie no Pantanal (Morato et al., 2006; Cavalcanti, 2010). Além da busca por um diálogo com os produtores rurais, através de workshops e outros encontros, há nesse campo uma clara demanda por estudos sobre a percepção local, que vêm ganhando importância ao longo das últimas décadas. 
Quinze anos depois da minha primeira experiência no Pantanal, com a qual comecei este artigo, a situação das onças na região permanece difícil. Os projetos conservacionistas certamente mitigaram conflitos e trouxeram novas práticas, mas seu alcance é limitado. Com a intensificação da produção, a caça ainda é comum na maior parte da região. Mas novos problemas importantes surgiram para a conservação. O Pantanal está enfrentando grandes incêndios a cada estação seca nos últimos anos, efeito somado das mudanças climáticas, do desmatamento e da sabotagem do sistema de proteção ambiental pelo governo brasileiro atual. Tudo isso gera um quadro bastante sombrio em termos de conservação, não só para as onças, mas para o bioma como um todo.

Procurei abordar aqui a ressignificação de certas práticas tradicionais de caça no interior de projetos conservacionistas, incluindo aí o uso de cães em capturas científicas e o contraste entre o animal nocivo e a espécie ameaçada. A partir de uma tradição que remonta aos caçadores-naturalistas do início do século XX, pude caracterizar um modo de relação com a onça-pintada que contrasta com os paradigmas atuais, estabelecidos desde a entrada em cena dos projetos conservacionistas na região.

A caça, seja ela definida em termos culturais seja em termos utilitários, é uma realidade que persiste e com a qual a perspectiva conservacionista precisou necessariamente lidar. Em certos casos, como vimos, inclusive incorporando e subvertendo-a. Nesse sentido, para tematizar os contrastes e linhas de continuidade entre práticas de caça e de conservação ligadas à onça-pintada, o tema do conflito humano-fauna parece limitado. Ele é antes de um contexto de efetuação entre outros, os quais incluem também alianças e formas de colaboração. 


\section{REFERÊNCIAS BIBLIOGRÁFICAS}

Almeida, A. de (1976) Jaguar hunting in Mato Grosso. England: Stanwill Press.

Banducci JR., Álvaro (1995) A natureza do pantaneiro - Relações sociais e representação de mundo entre vaqueiros do Pantanal. Dissertação em Antropologia Social, USP.

Benevides, Cezar, e Leonzo, Nanci (1999) Miranda Estância. Ingleses, peões e caçadores no Pantanal mato-grossense. Rio de Janeiro: FGV Editora.

Campos Filho, Luiz Vicente da Silva (2002) Tradição e ruptura - Cultura e Ambiente Pantaneiros. Cuiabá: Entrelinhas.

Cavalcanti, Sandra M. C., Marchini, Silvio, Zimmermann, Alexandra, Gese, Eric M., e Macdonald, David W. (2010) Jaguars, Livestock, and People in Brazil: Realities and Perceptions Behind The Conflict. USDA National Wildlife Research Center. Staff Publications. Paper 918. University of Nebraska.

Crawshaw, Peter G (2006) "The history of carnivore research in Brazil”. Em Morato, Ronaldo Gonçalves (org.). Manejo e Conservação de Carnívoros Neotropicais. São Paulo: Edições Ibama, pp. 15-38.

Crawshaw, Peter G., e Quigley, Howard B. (1984) "A ecologia do jaguar ou onça pintada (panthera onca palustris) no pantanal matogrossense". Em Estudos bioecológicos do pantanal matogrossense -relatório final-parte I. Brasília: Instituto Brasileiro de Desenvolvimento Florestal - IBDF.

- - (1991) "Jaguar spacing, activity and habitat use in a seasonally flooded environment in Brazil”. The Zoological Society of London, 223: 358-369.

Desbiez, A. L. J.J; Keuroghlian, A.; Piovezan, U.; Bodmer, R. E. (2009) "Ecologia de populações de porco monteiro no Pantanal do Brasil". Disponível em: https://www. embrapa.br/busca-de-publicacoes/-/publicacao/853316/ecologia-de-populacoes-deporco-monteiro-no-pantanal-do-brasil.

Furtado, Mariana M.; Pescastegui, Samia E.; Jácomo, Anah Tereza A; Powell, George; Silveira, Leandro; Vynne, Carly; Sollmann, Rahel (2008) "Studying Jaguars in the Willd: Past Experiences and Future Perspectives". En The Jaguar In Brasil. Cat News, Special Issue No 4. IUCN, Cat Specialist Group, Jaguar Conservation Fund. Bern, Switzerland. pp. 41-47.

Guimarães Rosa, João (2001) “Meu tio o Iauaretê”. In: Estas Estórias. 5. ed. Rio de Janeiro: Nova Fronteira, pp. 191-235. 
Haraway, Donna (1989) "Teddy bear patriarchy taxidermy in the garden of eden, New York City, 1908-1936”. Primate visions: Gender, race, and Nature in the World of Modern Science. London: Routledge, pp. 26-58.

Lourival, Reinaldo, e Fonseca, Gustavo (1997) "Análise de sustentabilidade do modelo de caça tradicional, no Pantanal da Nhecolândia, Corumbá, (MS)”. En Valladares-Pádua, C.; Bodmer, R.E. \& Cullen Jr., L. Manejo e Conservação de vida silvestre no Brasil. Belém: Sociedade Civil Mamirauá.

Marvin, Garry (2002) "Unspeakability, inedibility, and the structures of pursuit in the english foxhunt”. En Nigel Rothfels (orgs.), Representing animals. Indiana University Press, pp 139-158.

Mazza, Maria Cristina Medeiros; Mazza, Carlos Alberto da Silva; Sereno, José Robson Bezerra; Santos, Sandra Aparecida; Pellegrin, Aiesca Oliveira (1994) Etnobiologia e conservação do bovino pantaneiro. Corumbá: CPAP/ EMBRAPA.

Millard, Candice (2007) O Rio da Dúvida - A sombria viagem de Theodore Roosevelt e Rondon pela Amazônia. São Paulo: Companhia das Letras.

Morato, Ronaldo Gonçalves (org.) (2006) Manejo e Conservação de Carnívoros Neotropicais. São Paulo: Edições Ibama.

Morato, R. G., Beisiegel, B. D. M., Ramalho, E. E., Campos, C. B. de, \& Boulhosa, R. L. P. (2013) "Avaliação do risco de extinção da onça-pintada Panthera onca (Linnaeus, 1758) no Brasil”. Biodiversidade Brasileira, 3(1): 122-132.

Oliveira, Jorge Eremites de (1996) Guató: argonautas do pantanal. Porto Alegre: EDIPUCRS.

Papavero, Nelson (2017) "Nomes populares conferidos à Panthera onca (Linnaeus, 1758) (Mammalia, Carnivora, Felidae) no Brasil”. Arquivos De Zoologia, 48(2): 37-93.

Pereira Da Cunha, Comandante H. (1922) Viagens e caçadas em Mato Grosso. Rio de Janeiro: Livraria Francisco Alves.

Roosevelt, Theodore (1976 [1914]) Nas Selvas do Brasil. Rio de Janeiro: Itatiaia

Schaller, George B. (2007) A naturalist and other beasts: tales from a life in the field. San Francisco: Sierra Club Books.

Siemel, Sasha (1953) Tigrero! New York: Ace Books. 
Silveira, Leandro; Boulhosa, Ricardo; Astete, Samuel; Jácomo, Anah Tereza de Almeida (2008) "Management of domestic livestock predation by jaguars in Brazil". En: Cat News - The jaguar in Brazil - Special issue n. 4. Switzerland: IUCN/ Cat Specialist Group, pp. 26-30.

Süssekind, Felipe (2014) O Rastro da Onça: relações entre humanos e animais no Pantanal. Rio de Janeiro: 7 Letras.

Tsing, Anna Lowenhaupt (2005) Friction: An Ethnography of Global Connection. Princeton/Oxford: Princeton University Press. 